\title{
Interlocking Shish-Kebab Morphology in Polybutene-1
}

\author{
G. KALAY, C. R. KALAY \\ Department of Chemistry, Bilkent University, Bilkent, Ankara 06533, Turkey
}

Received 24 January 2002; revised 3 June 2002; accepted 11 June 2002

\begin{abstract}
The aim of this research was to explore the effect of shear-controlled orientation injection molding (SCORIM) on polybutene-1 (PB-1). This article describes the methods and processing conditions used for injection molding and discusses the properties of the moldings. Both conventional and SCORIM have been used for the production of moldings. SCORIM is based on the application of specific macroscopic shears to a solidifying melt that facilitates enhanced molecular alignment. The effect of the process was investigated by performing mechanical tests, X-ray studies, differential scanning calorimetric studies, polarized light microscopy, and atomic force microscopy (AFM). Moldings exhibited an improved mechanical performance as compared with conventional moldings. Young's modulus was increased over twofold, and the impact energy was enhanced by $60 \%$. The improvement in mechanical performance was combined with an increase in crystallinity and enhanced molecular orientation. The application of SCORIM also favored the formation of the stable Form I' in PB-1. The formation of interlocking shish-kebab morphology following the application of SCORIM was observed in the AFM studies. Relationships between the mechanical properties of PB-1 and the micromorphologies formed during processing are demonstrated. () 2002 Wiley Periodicals, Inc. J Polym Sci Part B: Polym Phys 40: 1828-1834, 2002

Keywords: polybutene-1; poly(1-butene); injection molding; shear-controlled orientation injection molding (SCORIM); structure-property relations; orientation
\end{abstract}

\section{INTRODUCTION}

Shear-controlled orientation in injection molding (SCORIM) has been reported to be effective in the enhancement of physical properties of semicrystalline polymers by morphology management. ${ }^{1-6}$ The application of macroscopic shears to a solidifying semicrystalline melt produces more pronounced molecular alignment that leads to increased orientation in the resulting microstructure. As a result, the solidified polymer exhibits enhanced crystallinity accompanied by enhanced stiffness. Furthermore, SCORIM allows this increase in stiffness to be achieved without loss of impact strength for some of the materials investigated. ${ }^{1-4}$ The microstructure of SCORIM mold-

\footnotetext{
Correspondence to: G. Kalay (E-mail: gkalay@fen.bilkent. edu.tr)

Journal of Polymer Science: Part B: Polymer Physics, Vol. 40, 1828-1834 (2002) () 2002 Wiley Periodicals, Inc.
}

ings may exhibit shish-kebab morphology $y^{2,3,7}$ depending on the processing conditions applied. A detailed account of the appearance of the shishkebab morphology in SCORIM moldings has been given for isotactic polypropylene. ${ }^{3}$

Polybutene-1 (PB-1) is a semicrystalline isotactic thermoplastic polyolefin with high molecular weight synthesized from butene-1 monomer with Ziegler-Natta-type catalyst. PB-1 has a singular crystallization behavior. The crystallization behavior has been extensively researched..$^{8-24}$ Natta et al. ${ }^{8}$ discovered that on crystallizing from the melt, PB first assumes an 11/3 helical conformation with a tetragonal unit cell. This crystalline structure (known as Form II) is unstable and, at room temperature and atmospheric pressure, it transforms into a stable 3/1 helix conformation (Form I) with a hexagonal (rhombohedral) unit cell. This process is called aging, which profoundly changes the properties of the material. In 
addition to the increase of the crystalline melting point $\left(120^{\circ} \mathrm{C}\right.$ for Form II and $135^{\circ} \mathrm{C}$ for Form I), the material becomes more rigid and displays higher strength after this transformation. ${ }^{9}$

Nakafuku and Miyaki ${ }^{10}$ investigated the effect of pressure on the crystallization behavior of isotactic PB-l and reported that the melt crystallization of $\mathrm{PB}$ under high pressure produces a stable form (Form I') that shows the same X-ray diffraction pattern as Form I but has a much lower melting temperature (96 vs $130{ }^{\circ} \mathrm{C}$ ) at atmospheric pressure.

The aim of this research is to demonstrate the effect of SCORIM on a particular PB grade and to investigate the relationship between microstructure and mechanical performance. It was of particular interest to examine the formation of shishkebab morphology following SCORIM.

\section{PROCESSING AND EXPERIMENTAL PROCEDURE}

\section{Materials}

The material investigated was an unfilled PB-1 polymer supplied by Shell Research SA (Louvain-laNeuve, Belgium). The material exhibits a melt flow index (MFI) of $0.4 \mathrm{~g} / 10 \mathrm{~min}$ and a density of 0.93 $\mathrm{g} / \mathrm{cm}^{3}$. It has a melting range of $122-128{ }^{\circ} \mathrm{C}$ and a Vicat softening temperature of $113{ }^{\circ} \mathrm{C}$. The investigated PB-1 grade was developed especially for use in hot water pipes.

\section{Injection Molding}

Both conventional injection molding and SCORIM were used in processing. Width-waisted round tensile test bars with a 5-mm diameter and a 15-mm gauge length were molded. A Demag 150 injection-molding machine equipped with a double live-feed molding device was used for the production of bars. ${ }^{2}$ One set of conventional moldings (CMPB) and one set of SCORIM moldings (SCPB) were produced. The general processing conditions for these moldings are summarized in Table 1. The maximum cavity pressure recorded during the production of conventionally molded samples (CMPB) was 288 bars. SCORIM moldings were produced with repeated shear actions under an average cavity pressure of 329 bars.

The samples were stored under room conditions after molding. All of the tests were performed on 3-week-old samples unless otherwise
Table 1. Processing Conditions for the Conventional (CM-) and SCORIM (SC-) PB Moldings

\begin{tabular}{lrc}
\hline & CMPB & SCPB \\
\hline Injection pressure (bar) & 76 & 100 \\
Holding pressure (bar) & 50 & 50 \\
Injection time (s) & 5 & 0.53 \\
Holding pressure time (s) & 30 & 53 \\
Cycle time (s) & 90 & 84 \\
Mold temperature $\left({ }^{\circ} \mathrm{C}\right)$ & 40 & 40 \\
Melt temperature $\left({ }^{\circ} \mathrm{C}\right)$ & 200 & 200 \\
Cavity pressure (bar) & 288 & 329 \\
\hline
\end{tabular}

stated. The differential scanning calorimetric (DSC) scans were obtained when reinvestigating the samples after 3 years.

\section{Mechanical Testing}

An Instron 4500 Series tensile-testing machine at a crosshead speed of $25 \mathrm{~mm} / \mathrm{min}$ and a test temperature of $23{ }^{\circ} \mathrm{C}$ was used in tensile testing. Stress-strain curves and Young's modulus were measured with a clip-on strain gauge.

An unnotched flexural Charpy impact test was performed to determine the impact on a Ceast Charpy flexural impact-testing machine. The initial span was $22 \mathrm{~mm}$, and the tests were done after cooling the samples down to $-20{ }^{\circ} \mathrm{C}$.

Tensile- and impact-testing results reported in this article were obtained after 1 month of injection molding the samples. Five samples were tested both in tensile and impact testing.

\section{Microtomy and Light Microscopy}

Thin sections of approximately $10-\mu \mathrm{m}$ thickness were prepared with a Leitz rotary microtome. A tungsten carbide-hardened steel knife of small included angle was used to cut thin sections. The knife and the specimen were maintained at room temperature. Sections were cut from planes parallel and transverse to the injection direction. The thin sections were mounted in immersion oil and contained between a glass slide and a cover slip. A soft brush was used to obtain the sections before they curled. Then the samples were examined with a Leitz polarized light microscope.

\section{Wide-Angle X-ray Diffraction (WAXD)}

$\mathrm{Cu} \mathrm{K} \alpha$ radiation was used for both X-ray diffractometry and the production of Debye patterns. 
The Debye patterns were used to record preferred orientation. For the conventional and SCORIM moldings the samples used were $1.5 \mathrm{~mm}$ thick and cut parallel to the injection direction. Debye patterns were recorded at positions of $1.5 \mathrm{~mm}$ from the edge of the moldings. A $100-\mu \mathrm{m}$-diameter aperture was used to define the position and cross section of the incident X-ray beam.

For the diffractometer studies, the incident Xray beam was incident on a longitudinal section. Diffraction profiles were recorded when scanning at a rate of $0.02^{\circ} 2 \theta / \mathrm{s}$ over an angular range of $7^{\circ}$ $<2 \theta<50^{\circ}$.

The crystallinities of the samples were determined from the diffractometer profiles. The summation of the crystalline peak areas is divided by the total area under the diffractometer scan and multiplied by 100 . The crystallinity values are subject to the approximations imposed by the constraints of working with anisotropic samples, and accordingly the results quoted are the relative crystallinities.

\section{DSC}

A Setaram Labsys ${ }^{\mathrm{TM}}$ DSC12 was used for measuring the DSC thermograms. Approximately $15 \mathrm{mg}$ of samples were cut from the middle point of the gauge length of each molding and sealed in aluminium pans. A heating rate of $10{ }^{\circ} \mathrm{C} / \mathrm{min}$ was applied.

\section{Atomic Force Microscopy (AFM)}

AFM studies were carried out at Shell Research and Technology Centre, Amsterdam, by Dr. Constant A. J. Putman. The samples were prepared by etching for 4 min with a permanganic etchant. AFM was operated in the tapping mode.

\section{EXPERIMENTAL RESULTS AND DISCUSSION}

\section{Mechanical Properties}

Table 2 lists the tensile-test and impact-test data for the conventional (CMPB) and SCORIM

Table 2. Mechanical Test Results from Tensile and Impact Testing of Conventional (CMPB) and SCORIM (SCPB) Moldings of the Investigated PB Grade (Standard Deviation Given in Brackets)

\begin{tabular}{lcc}
\hline & CMPB & SCPB \\
\hline Young's modulus $(\mathrm{MPa})$ & $970( \pm 250)$ & $2520( \pm 280)$ \\
Impact energy $(\mathrm{J})$ & $1.53( \pm 0.24)$ & $2.45( \pm 0.13)$ \\
\hline
\end{tabular}

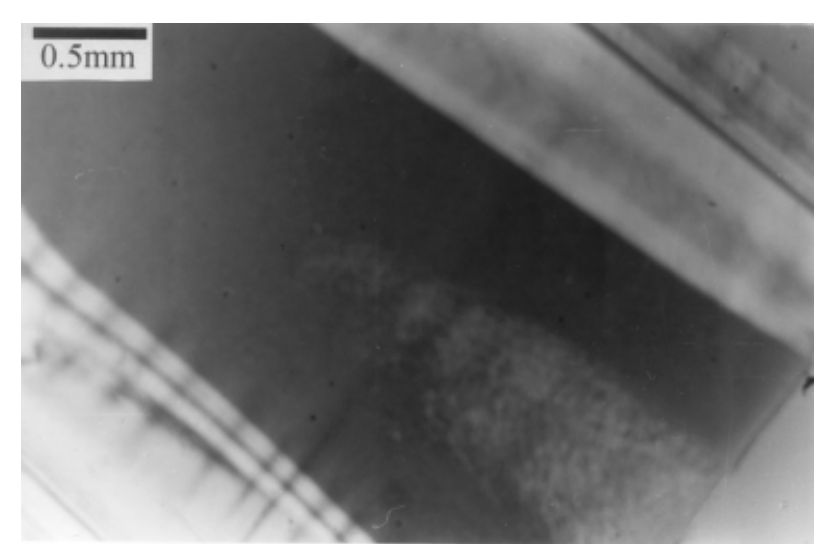

Figure 1. Microstructure of the longitudinal cross section of CMPB.

(SCPB) moldings. CMPB exhibits $970 \mathrm{MPa}$ Young's modulus, whereas SCPB exhibits 2500 MPa Young's modulus. This accounts for more than a twofold increase following SCORIM. The flexural Charpy impact testing revealed a $60 \%$ increase in impact strength of PB following SCORIM processing. The impact energy for breaking conventionally molded $\mathrm{PB}$ is $1.53 \mathrm{~J}$, whereas it is $2.45 \mathrm{~J}$ for the SCPB moldings.

\section{Polarized Light Micrsocopy Results}

Figures 1 and 2 illustrate the longitudinal cross sections of the CMPB and SCPB moldings. The contrast in CMPB indicates the flow characteristic in conventional molding. The structure in SCPB is more homogeneous and does not exhibit any contrast when viewed between cross polars, unlike CMPB. Studies done at higher magnification reveal a finely grained spherulitic morphol-

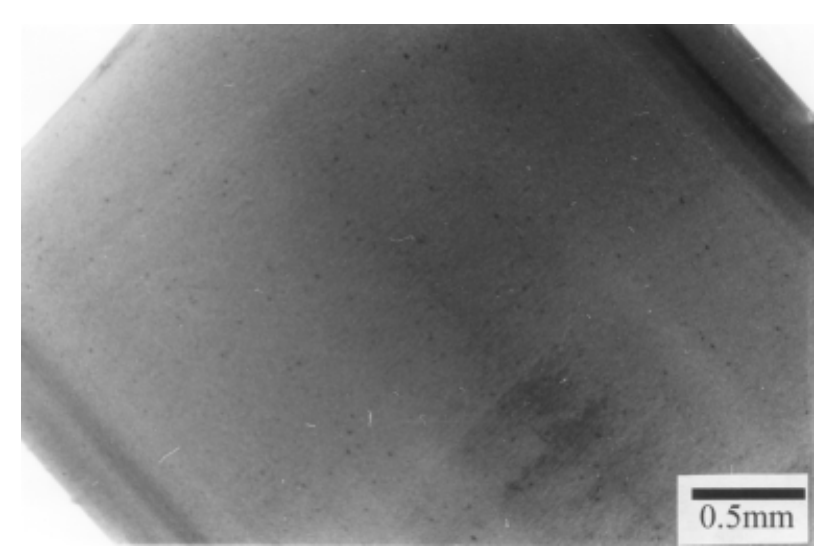

Figure 2. Microstructure of the longitudinal cross section of SCPB. 


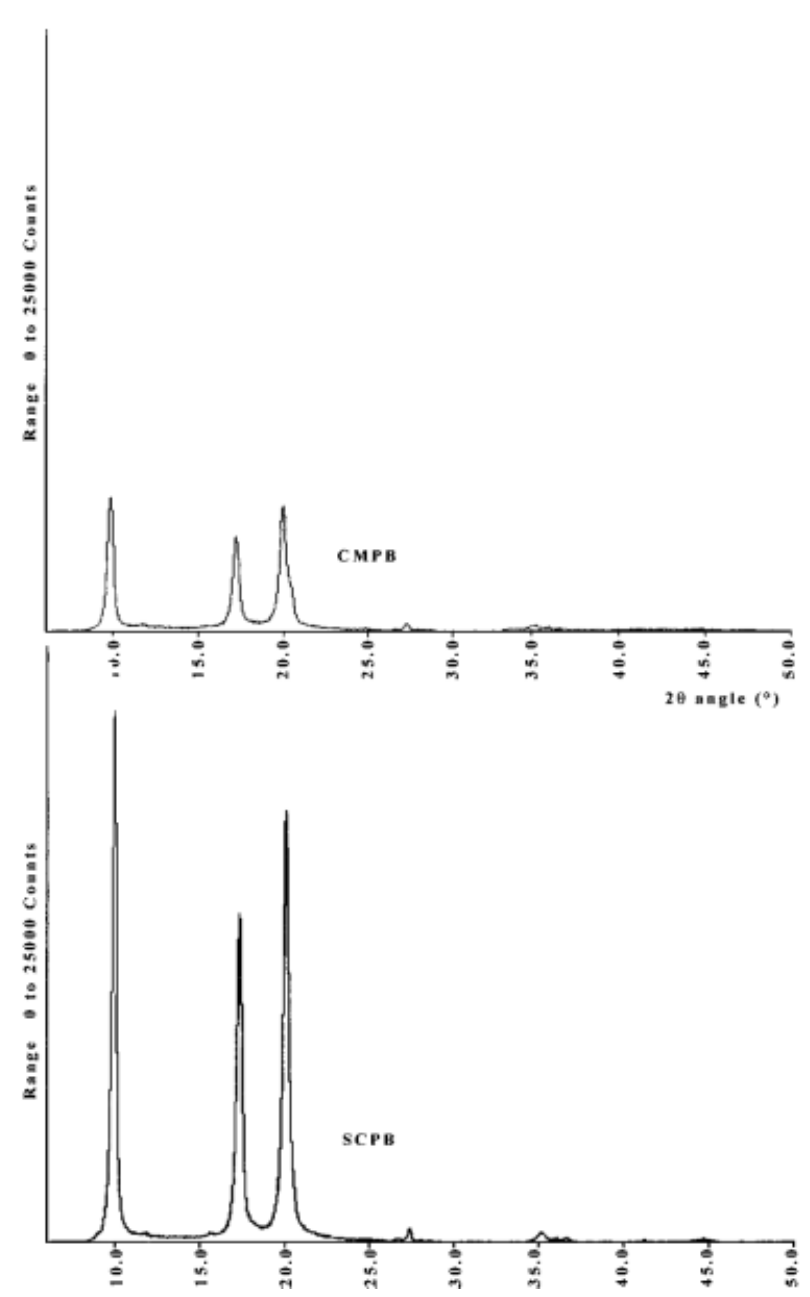

Figure 3. WAXD profiles of a SCORIM (SCPB) and a conventional molding (CMPB) for comparison.

ogy in both types of moldings. The spherulitic morphology of SCPB exhibits a more homogeneous distribution of spherulites, whereas the morphology of CMPB shows distinctive bands at an even higher magnification.

\section{X-ray Diffraction Profiles and Debye Patterns}

$\mathrm{X}$-ray studies were primarily carried out to determine the crystallinity and molecular orientation. Additional information was gained about the crystal modifications present in the samples. The analysis of the WAXD profiles (Fig. 3) suggests that SCPB exhibits greater crystallinity than CMPB. SCPB is $80 \%$ crystalline, whereas CMPB is $71 \%$ crystalline. Both WAXD profiles, the one from the conventional molding and the one from the SCORIM molding, exhibit three strong reflections corresponding to the (110), (300), and (220) reflections of the hexagonal unit cell found in Form $\mathrm{I}^{8}$ and Form $\mathrm{I}^{\prime} .{ }^{25}$ The WAXD profile of the conventional moldings indicate three more smaller peaks at a $2 \theta$ angle of $28,35.6$, and $36.3^{\circ}$. The peak at $28^{\circ}$ corresponds to the (410) reflection of the hexagonal modification. ${ }^{8}$ The peaks at 35.6 and $36.3^{\circ}$ are broader and less clearly determinable. They are assumed to belong to the (600) and (520) reflections of the hexagonal modification, although the peaks are shifted by about $1.5-2^{\circ}$ in their $2 \theta$ values as compared with the values listed by Natta et al. ${ }^{8}$ whose work was used in indexing the reflections.

The WAXD profile of the SCORIM moldings, that is, SCPB, exhibit additional smaller peaks at a $2 \theta$ angle of $28.4,36.2,37.6$, and $45.7^{\circ}$. The peak at $28.4^{\circ}$ corresponds to the (410) reflection, which is also found in the WAXD profile of the conventional molding. The peak at $45.7^{\circ}$ is only visible in the SCORIM profile and can be attributed to the (440) reflection of the hexagonal modification. ${ }^{8}$ The peaks at 36.2 and $37.6^{\circ}$ represent the (600) and (520) reflections of that same modification. The agreement with the literature data is better in this case than in the case of the WAXD profile of the conventional molding.

There is no indication of molecular orientation in the Debye pattern of CMPB (Fig. 4). SCPB is very highly oriented as evident from the strong arcing in the Debye pattern [Fig. 5(a)]. The Debye

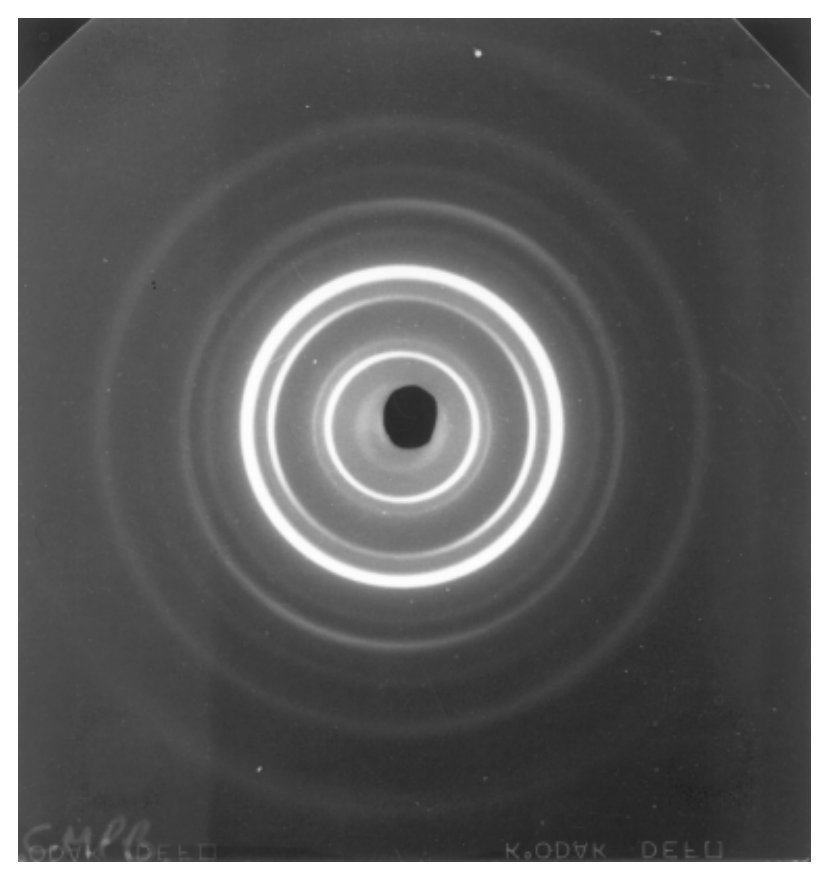

Figure 4. X-ray Debye pattern of CMPB. 

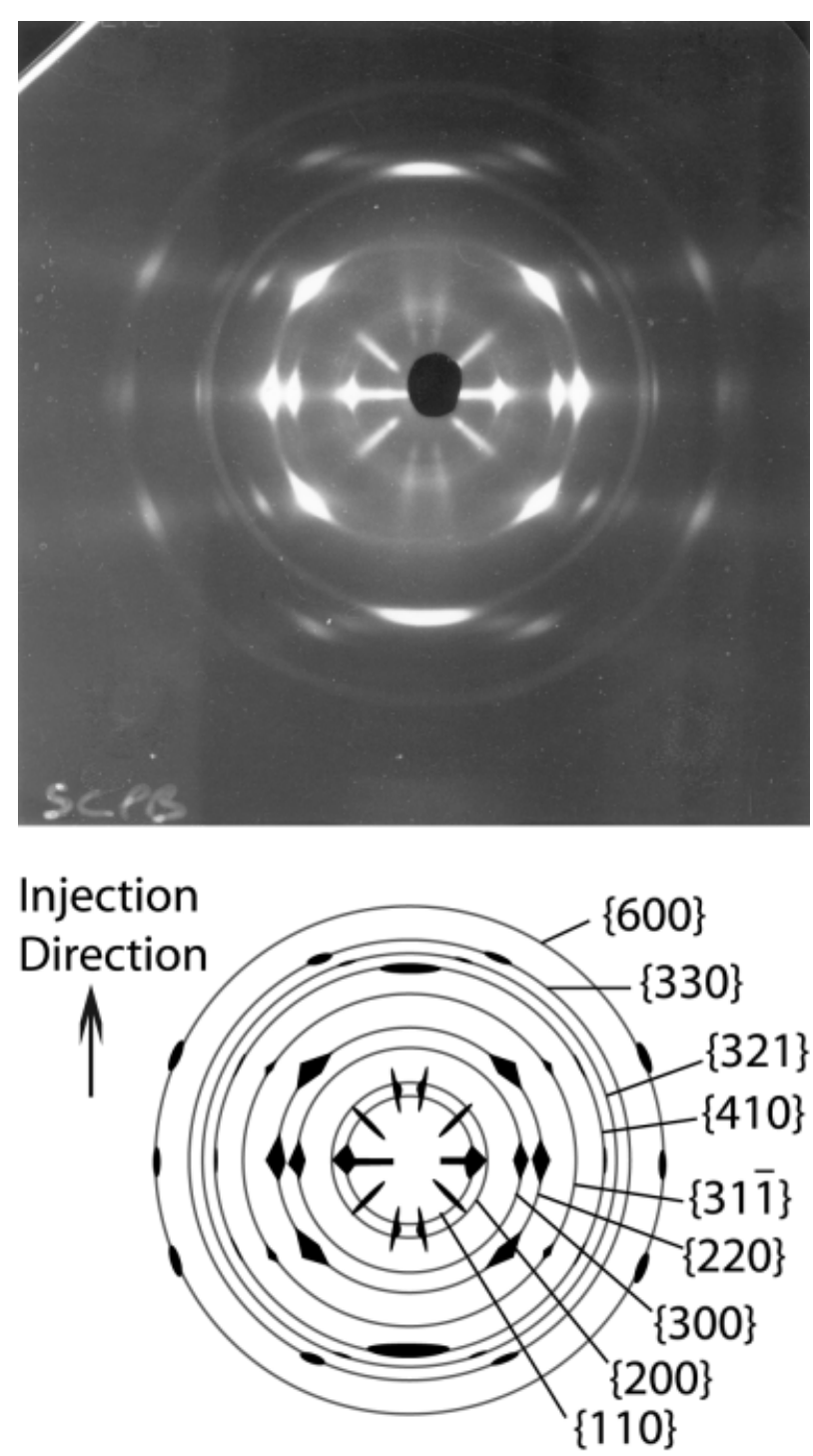

Figure 5. (a) X-ray Debye pattern of SCPB and (b) schematic representation of the Debye pattern shown in (a).

pattern of SCPB is represented in Figure 5(b). The rings are identified from the inner to the outer ring- $\{110\},\{200\},\{300\},\{220\},\{311\},\{410\}$, $\{321\},\{330\}$, and $\{600\}$. All of them, except for $\{200\}$, are reflections of the hexagonal modification. The appearance of a weak $\{200\}$ reflection indicates traces of the tetragonal Form II, ${ }^{26}$ meaning that after 3 weeks of storage the transformation from Form I to II was still incomplete. The Debye pattern contains most of the reflections visible in the WAXD profile. There are two additional reflections in the smaller-angle range, $\{311\}$ and $\{321\}$, whereas the $\{520\}$ and $\{440\}$ reflections cannot be identified from the Debye pattern.
The Debye pattern of the conventional molding CMPB exhibits all the reflections visible in the Debye pattern of SCPB with the exception of the $\{321\}$ reflection, which is only present in the Debye pattern of SCPB. In contrast with the WAXD profile of CMPB, the Debye pattern of CMPB does not reveal a ring corresponding to the $\{520\}$ reflection. Its outermost ring corresponds to the $\{440\}$ reflection, otherwise only identifiable in the WAXD profile of the SCORIM molding. Like the Debye pattern of SCPB, the Debye pattern of the conventional molding also exhibits a $\{200\}$ reflection belonging to Form II, which is further indication of the incomplete transformation from Form I to II, when the patterns were gained from samples.

\section{DSC Results}

In the published literature Form I and Form I' show the same X-ray diffraction pattern, while differing in their melting behavior. ${ }^{25}$ Therefore, an additional DSC study was performed to determine the possible presence of Form I' in the SCORIM samples. Figure 6 represents the DSC thermograms for CMPB and SCPB. The thermogram of the conventional molding CMPB exhibits a single melting peak at $133.9{ }^{\circ} \mathrm{C}$ that corresponds to the melting of Form I. There is no indication of Form II melting. The DSC study was carried out long after the X-ray studies, and by then the transformation from Form I to Form II was completed.

SCPB exhibits two melting peaks. The first melting phenomenon occurs between 75 and 96

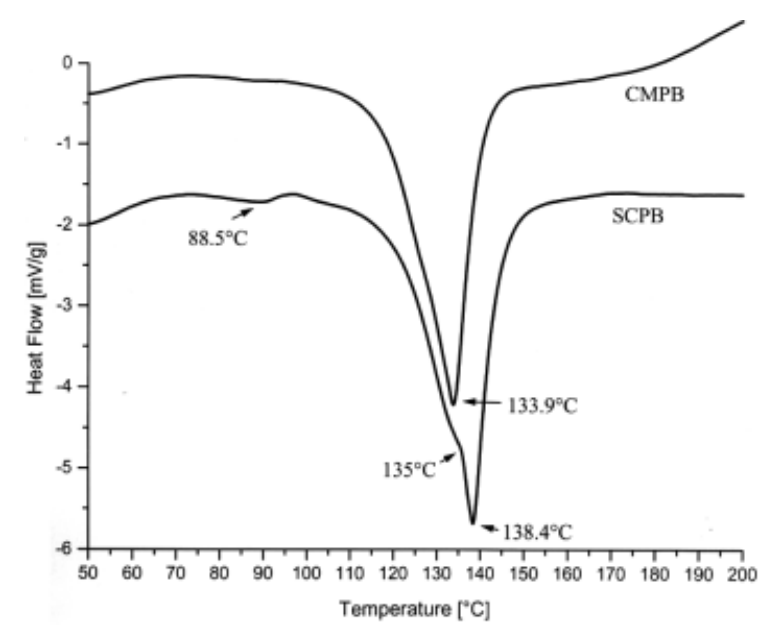

Figure 6. DSC thermograms for SCORIM (SCPB) and conventional moldings (CMPB). 


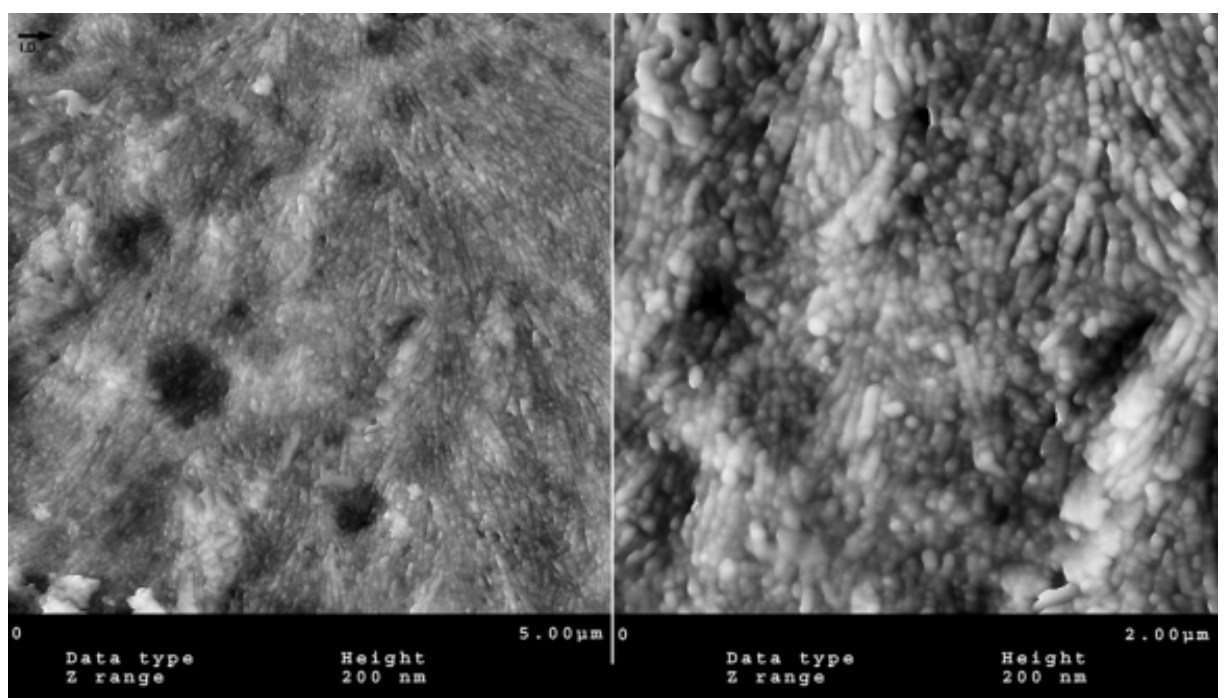

Figure 7. AFM image of the core region of SCPB. The injection direction (I.D.) is identified by an arrow.

${ }^{\circ} \mathrm{C}$, peaking at $88.5{ }^{\circ} \mathrm{C}$, and corresponds to the melting of Form I'. The main melting peak, related to Form I melting, is shifted to a higher temperature as compared with the DSC results of CMPB; it appears at $138.4{ }^{\circ} \mathrm{C}$. The main melting peak exhibits a low-temperature shoulder in the range of $130-135^{\circ} \mathrm{C}$, indicating a small amount of Form II present in the sample. In the literature ${ }^{25}$ Form I' melts and recrystallizes into Form II above $100{ }^{\circ} \mathrm{C}$. From the DSC result of the conventional molding (CMPB), it is known that the original transformation from Form II to Form I is complete. The appearance of an endothermic shoulder related to Form II melting in the DSC thermogram of SCPB is, therefore, a further indirect indication of the existence of Form $\mathrm{I}^{\prime}$ in the SCORIM-processed SCPB.

\section{AFM Results}

The main aim of the AFM studies was to obtain further structural information about the different regions in SCORIM-processed samples. AFM scans were done in the core region of the sample and in the shish-kebab region. The core region of the sample is spherulitic. The AFM images suggest that there is no preferred orientation. Figure 7 depicts the growth of crystalline lamellae in a spherulite. On the other hand, the shear region close to the edge of the sample clearly exhibits molecular orientation. The AFM images confirm the existence of shish-kebab morphology. A major finding of the AFM studies was the observation of interlocking shish-kebab morphology in the shear region. Figure 8 represents a high-resolution image of that region. It clearly demonstrates the interlocking pattern of kebabs growing from neighboring shishes. Kebabs engage with each other that can restrict molecular motion under the application of load. This morphology further explains the combined enhanced stiffness and toughness of SCORIM-molded PB-1.

\section{CONCLUSIONS}

This article has examined the effect of enhanced shearing during injection molding, as applied during SCORIM processing, on a particular grade of PB-1. The application of SCORIM leads to improvement in mechanical properties combined with an increase in crystallinity. Most importantly, the application of SCORIM affects stiffness and thoughness, evident through a more than twofold increase in Young's modulus and a 1.6 -fold increase in impact energy. The rise in cavity pressure during SCORIM processing also favors the formation of the stable Form I'.

The improvement in mechanical properties is related to changes in the micromorphology, as SCORIM leads to the formation of interlocking shish-kebab morphology in shear-influenced regions of the moldings.

The example of PB-1 demonstrates that the application of specified shears, as it is done in SCORIM, is effective in inducing micromorpholo- 


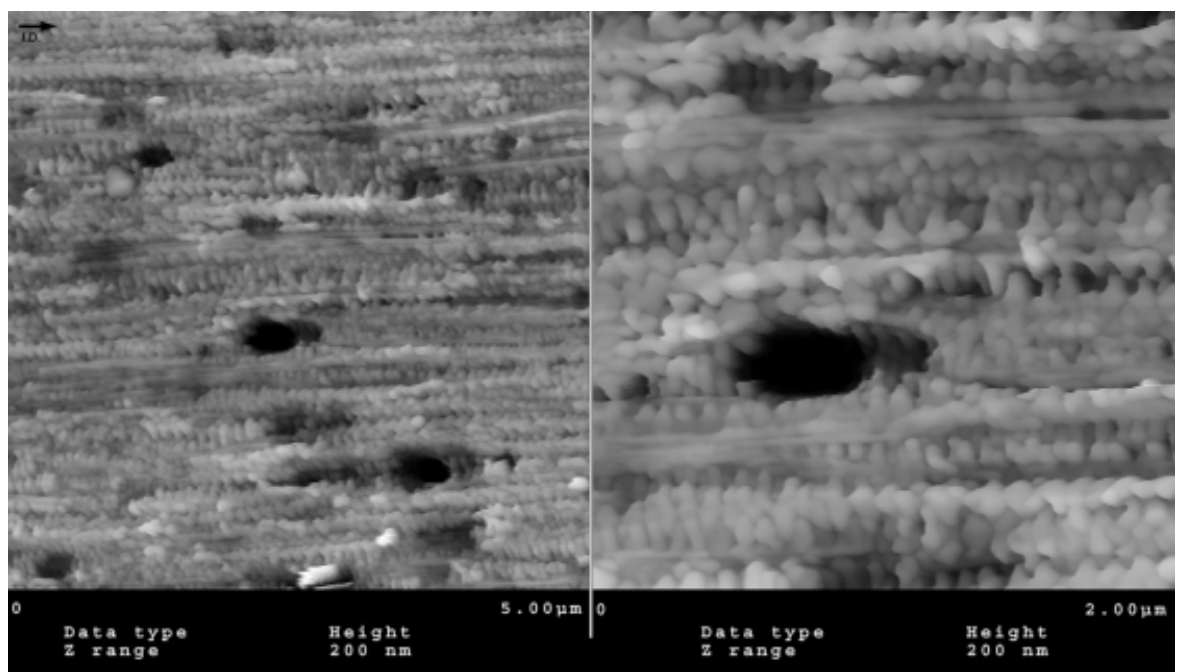

Figure 8. AFM image of the shear region of SCPB. The injection direction (I.D.) is identified by an arrow.

gies in particular regions of molded components that impart substantial enhancement of mechanical properties. A more detailed study on the processing and physical-property relationships of various grades of PB-1 and ethylene-butene- 1 copolymer is in progress. ${ }^{27}$

The processing and major part of this work were carried out in the Wolfson Centre for Materials Processing, Brunel University, where both authors were previously employed. The authors gratefully acknowledge the funding of the European Commission under the Brite-Euram Programme for the Decrypo Project (BE 95-2067).

\section{REFERENCES AND NOTES}

1. Kalay, G.; Allan, P. S.; Bevis, M. J. Kunstst 1997, 87(6), 768.

2. Kalay, G.; Bevis, M. J. J Polym Sci Part B: Polym Phys 1997, 35, 241.

3. Kalay, G.; Bevis, M. J. J Polym Sci Part B: Polym Phys 1997, 35, 265.

4. Kalay, G.; Bevis, M. J. J Polym Sci Part B: Polym Phys 1997, 35, 415.

5. Kalay, G.; Ogbonna, C. I.; Allan, P. S.; Bevis, M. J. Chem Eng Res Des 1995, 73, 798.

6. Kalay, G.; Sousa, R. A.; Reis, R. L.; Cunha, A. M.; Bevis, M. J. J Appl Polym Sci 1999, 73, 2473.

7. Keller, A.; Kolnaar, H. Mater Sci Technol 1997, 18, 191.

8. Natta, G.; Corradini, P.; Bassi, I. W. Nuovo Cimento 1962, 1, 52 .
9. Choi, S. Y.; Rakus, J. P.; O'Toole, J. L. Polym Eng Sci 1966, 6, 349.

10. Nakafuku, C.; Miyaki, T. Polymer 1983, 24, 141.

11. Kopp, S.; Wittmann, J. C.; Lotz, B. J Mater Sci 1994, 29, 6159.

12. Gohil, R. M.; Miles, M. J.; Petermann, J. J Macromol Sci Phys 1982, B21(2), 189.

13. Petermann, J.; Schultz, J. M. Colloid Polym Sci 1984, 262, 217.

14. Jandt, K. D.; McMaster, T. J.; Miles, M. J.; Petermann, J. Macromolecules 1993, 26, 6552.

15. Monasse, B.; Haudin, J. M. Makromol Chem Macromol Symp 1988, 20/21, 295.

16. Huang, Y.; Petermann, J. Polym Bull 1990, 24, 649.

17. Hsu, T. C.; Geil, P. H. J Macromol Sci Phys 1989, B28(1), 69.

18. Hong, W.; Spruiell, J. E. J Appl Polym Sci 1985, 30, 3163.

19. Boor, J., Jr.; Mitchell, J. C. J Polym Sci 1962, 62, 870 .

20. Fujiwara, Y. Polym Bull 1985, 13, 253.

21. Kopp, S.; Wittmann, J. C.; Lotz, B. Polymer 1994, $35,908$.

22. Kopp, S.; Wittmann, J. C.; Lotz, B. Polymer 1994, $35,916$.

23. Holland, V. F.; Miller, R. L. J Appl Phys 1964, 35, 3241.

24. Haas, T. W.; Maxwell, B. Polym Eng Sci 1969, 9, 225.

25. Armeniades, C. D.; Baer, E. J Macromol Sci Phys 1967, B1(2), 309.

26. Weynant, E.; Haudin, J. M.; G'sell, C. J Mater Sci 1982, 17, 1017.

27. Kalay, G.; Kalay, C. R. J Appl Polym Sci, manuscript submitted for publication, 2002. 